\title{
THE DEMONSTRATION OF PULMONARY ARTERIOVENOUS SHUNTS IN NORMAL HUMAN SUBJECTS, AND THEIR INCREASE IN CERTAIN DISEASE STATES *
}

\author{
By ANTHONY D. JOSE $\dagger$ AND WILLIAM R. MILNOR \\ (From the Department of Medicine, Johns Hopkins University and Hospital, \\ Baltimore, $M d$.)
}

(Submitted for publication April 28, 1959; accepted July 9, 1959)

The evidence for existence of arteriovenous shunts in the normal human lung is strong but necessarily indirect. Simultaneous measurements of oxygen tension in alveolar air and in arterial blood consistently show a degree of venous admixture in both normal and abnormal subjects (1), but no information has been obtained about the path taken by this unventilated blood. The passage of small glass or plastic beads through the pulmonary circulation has demonstrated potential pathways as large as $200 \mu$ in diameter $(2,3)$; but this technique involves an artificial distention of the vascular bed and gives no information about the extent to which such pathways may function physiologically.

The present investigation was based on the hypothesis that the decreased venous inflow to the right atrium and reduced blood flow through the pulmonary vessels during the Valsalva maneuver, as well as the rebound effects after release of the maneuver, might alter the flow through such shunts, and that this alteration could be detected by continuous measurement of the systemic arterial oxygen saturation. No distinction would necessarily be made by this technique between true arteriovenous anastomoses, with ventilation-perfusion ratio of zero, and poorly ventilated alveolar capillaries, with ventilation-perfusion ratio below the average for the whole capillary bed.

We have studied nine normal subjects, and 16 patients with cardiac or pulmonary disease; results in 12 additional patients with intracardiac shunts have been included for comparison.

\section{METHODS}

Ear oximetry proved unsatisfactory in recording changes in saturation during the Valsalva maneuver, ow-

\footnotetext{
* This investigation was supported in part by a grant from the American Heart Association.

$\dagger$ Present address: School of Medicine, Vanderbilt University, Nashville, Tennessee.
}

ing to the large variations in blood content of the ear caused by the maneuver. The Colson Model 103 cuvette densitometer ${ }^{1}$ was therefore used, recording the optical density of arterial blood at $620 \mathrm{~m} \mu$ wave length. As shown by Sabiston, Khouri and Gregg (4), in this portion of the spectrum the optical density of blood is a linear function of the per cent oxygen saturation of hemoglobin, provided no change in either hematocrit or velocity of blood flow through the cuvette occurs.

Patients were examined resting in the supine position. The cuvette densitometer was connected by approximately $20 \mathrm{~cm}$. of polyethylene tubing (internal diameter $=1.14$ $\mathrm{mm}$.) to a needle inserted into the brachial or femoral artery. Arterial blood was drawn through the cuvette by a motor-driven syringe at a constant rate, usually 0.3 $\mathrm{ml}$. per second. The output of the densitometer was recorded on one chanel of a Sanborn "Poly-Viso" or an "Electronics for Medicine" recorder. The sensitivity of the record was adjusted so that a 1 per cent change in oxygen saturation would produce a deflection of 1 to 2 $\mathrm{mm}$., using the neutral density wedge of the Colson cuvette as a guide.

Calibration of the record for each patient was calculated after completion of the test, when his arterial hematocrit had been determined. Since the change in optical density of blood for a given change in oxygen saturation depends on hemoglobin concentration, a calibration chart could be prepared to give the sensitivity of our instrument at different hematocrit levels. The error introduced by using hematocrit as an indication of hemoglobin concentration (i.e., assuming the same mean corpuscular hemoglobin concentration for all patients) is negligible for this purpose.

The calibration chart shown in Figure 1 was constructed from data obtained by in vitro measurements on four different human blood samples of widely different hematocrit values. In each sample the oxygen saturation was varied by aliquots of high and low saturation and the linear relation between optical density and oxygen saturation (4) determined. The slope of this line for each sample is plotted on the ordinate of Figure 1, and its hematocrit on the abscissa. Using this chart and a calibrating signal of known optical density on each record, the recorded deflections could be converted into changes in oxygen saturation. Figure 2 shows one of the original records, with the calculated sensitivity scale at-

1 The Colson Company, Elyria, Ohio. 


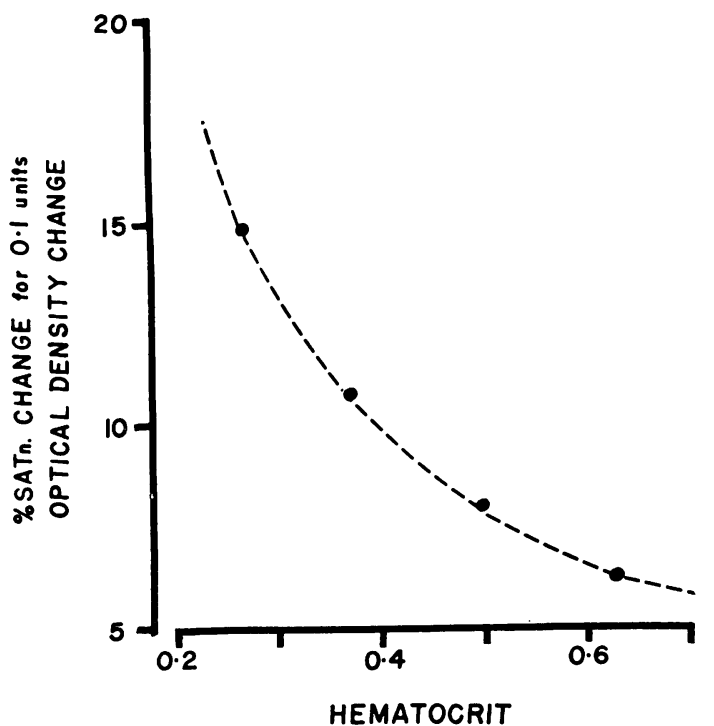

Fig. 1. Results Obtained by the IN Vitro Study of Four Human Blood Samples, Showing the Relationship Between Hematocrit and Densitometer Calibration

See text.

tached. To facilitate comparison, the records in Figure 3 have been replotted at uniform sensitivity.

A sample of arterial blood was taken immediately before each record and the control arterial oxygen saturation measured in a photometric oximeter (5) which was calibrated frequently with simultaneous Van Slyke determinations. Blood withdrawal through the cuvette was then begun, and after establishing a baseline on the record, the patient was asked to perform a previously rehearsed Valsalva maneuver, blowing through a mouth tube into a closed air chamber. A mercury manometer visible to the patient measured the pressure thus produced and the patient endeavored to keep this pressure at $40 \mathrm{~mm}$. $\mathrm{Hg}$ for 12 to 14 seconds. In most cases, special care was taken to avoid a deep inspiration before the maneuver; when this was neglected, a deflection related to this inspiration frequently appeared in the record of arterial saturation, preceding that related to the maneuver itself, (Patients E.J. and M.G., Figure 3).

In each case the mouth pressure developed during the test was recorded by a strain gauge and amplifier to give an approximate indication of the changes in intrathoracic pressure (6) which constitute the primary effect of the Valsalva maneuver.

Pulmonary arterial pressure was recorded in three patients in whom the study was performed during right heart catheterization.

Baseline stability in the group of normal subjects was such that no measurable saturation changes occurred during quiet respiration. In the group with heart or lung disease, those whose condition was primarily cardiac showed an equally stable baseline; three patients, in each of whom the primary pathology was in the lungs, showed regular changes in saturation synchronous with respiration and of magnitude 0.4 to 0.5 per cent on either side of the mean. Saturation was recorded in six patients during simple breath-holding for 12 seconds; in four no saturation change was found, while in two there was a fall in saturation, of 0.6 per cent in one and of 1.1 per cent in the other. Three rapid deep inspirations in the same six patients caused no change in saturation in four, a rise of 1.2 per cent in one and a rise of 1.8 per cent in one. In no case was there any difficulty in distinguishing the effect of the Valsalva maneuver on arterial saturation from the effects of simple respiration. This was equally true in the patients with intracardiac shunts, although those with "balanced" shunts frequently showed respiratory fluctuations in saturation as large as 2 per cent on either side of the mean.

The changes in optical density of blood observed during and after the Valsalva maneuver could theoretically be due to acute changes in hematocrit rather than changes in oxygen saturation, although hematocrit

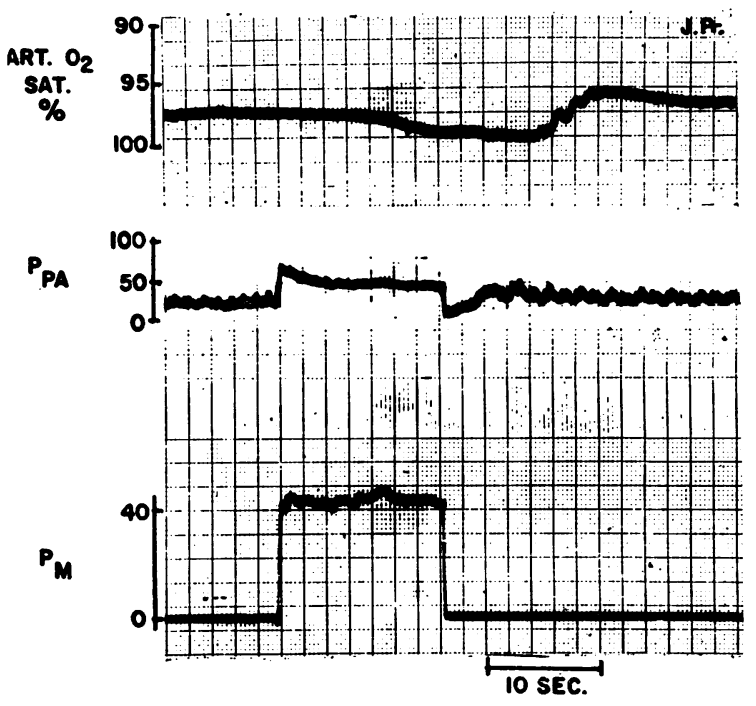

Fig. 2. Original Record, Showing Changes in Brachial Artery Oxygen Saturation (Art. O 2 Sat.), Pulmonary Artery Pressure (P $P_{\text {Aa }}$, m. Hg) and Mouth Pressure ( $P_{M}$, Mm. Hg.) During and After a Valsalva Maneuver in Patient J.Pr.

Effective pulmonary vascular perfusion pressure, estimated as the difference between mean pulmonary artery pressure and mouth pressure, falls from a control level of $24 \mathrm{~mm}$. $\mathrm{Hg}$ to $6 \mathrm{~mm}$. $\mathrm{Hg}$ within a few seconds after the onset of the Valsalva maneuver, maintains this level during the maneuver and rebounds temporarily to $38 \mathrm{~mm}$. $\mathrm{Hg}$ after release. Increased arterial saturation follows the decreased perfusion pressure during the maneuver, and decreased saturation below control levels follows the rebound elevation of perfusion pressure. The time lag of approximately five seconds between pressure and saturation changes presumably represents transit time of blood from pulmonary capillaries to peripheral artery. 

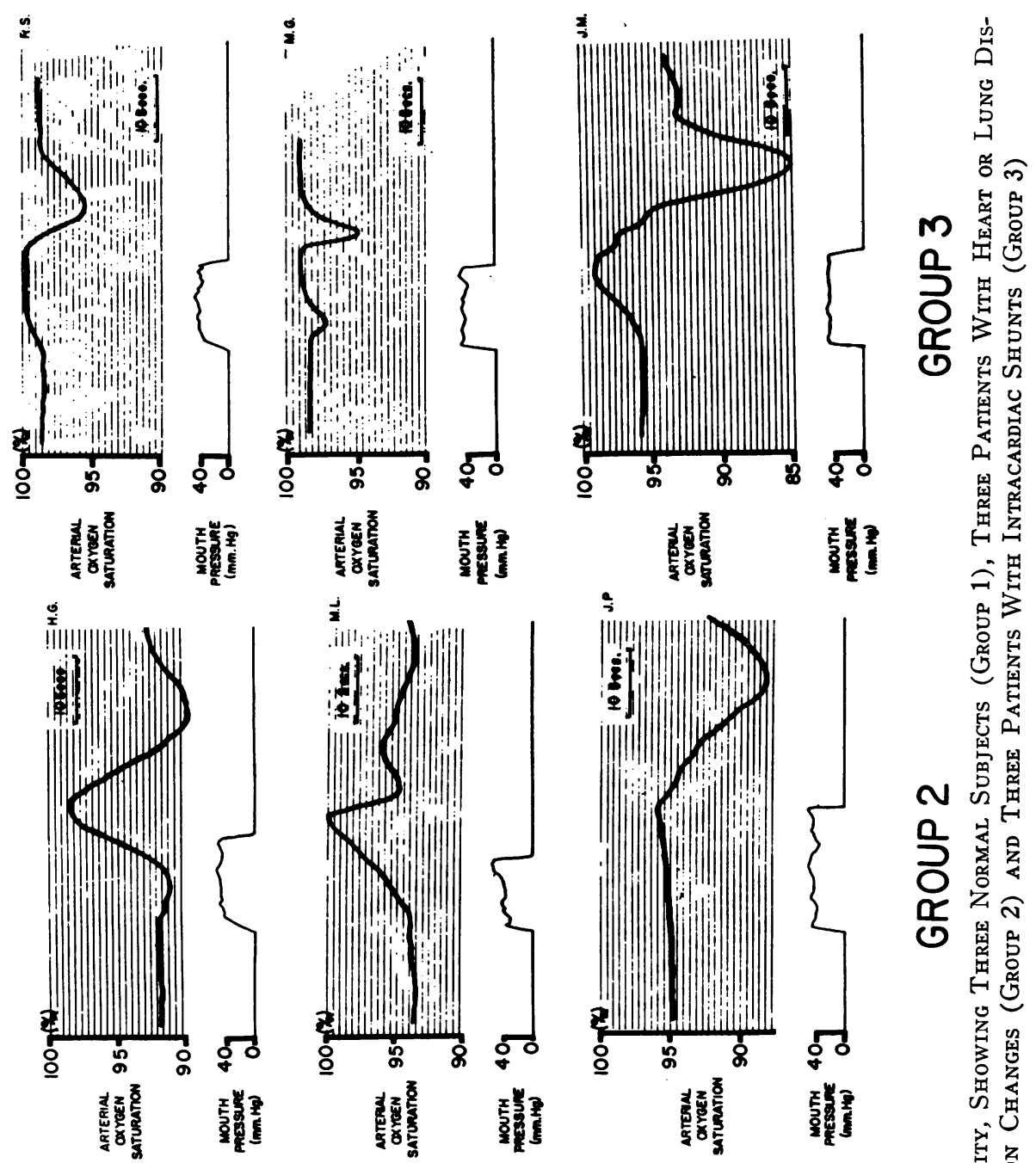

i

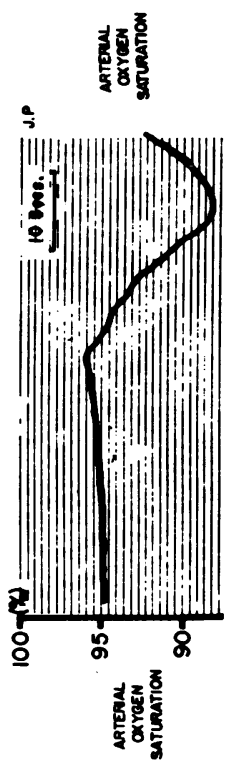

u
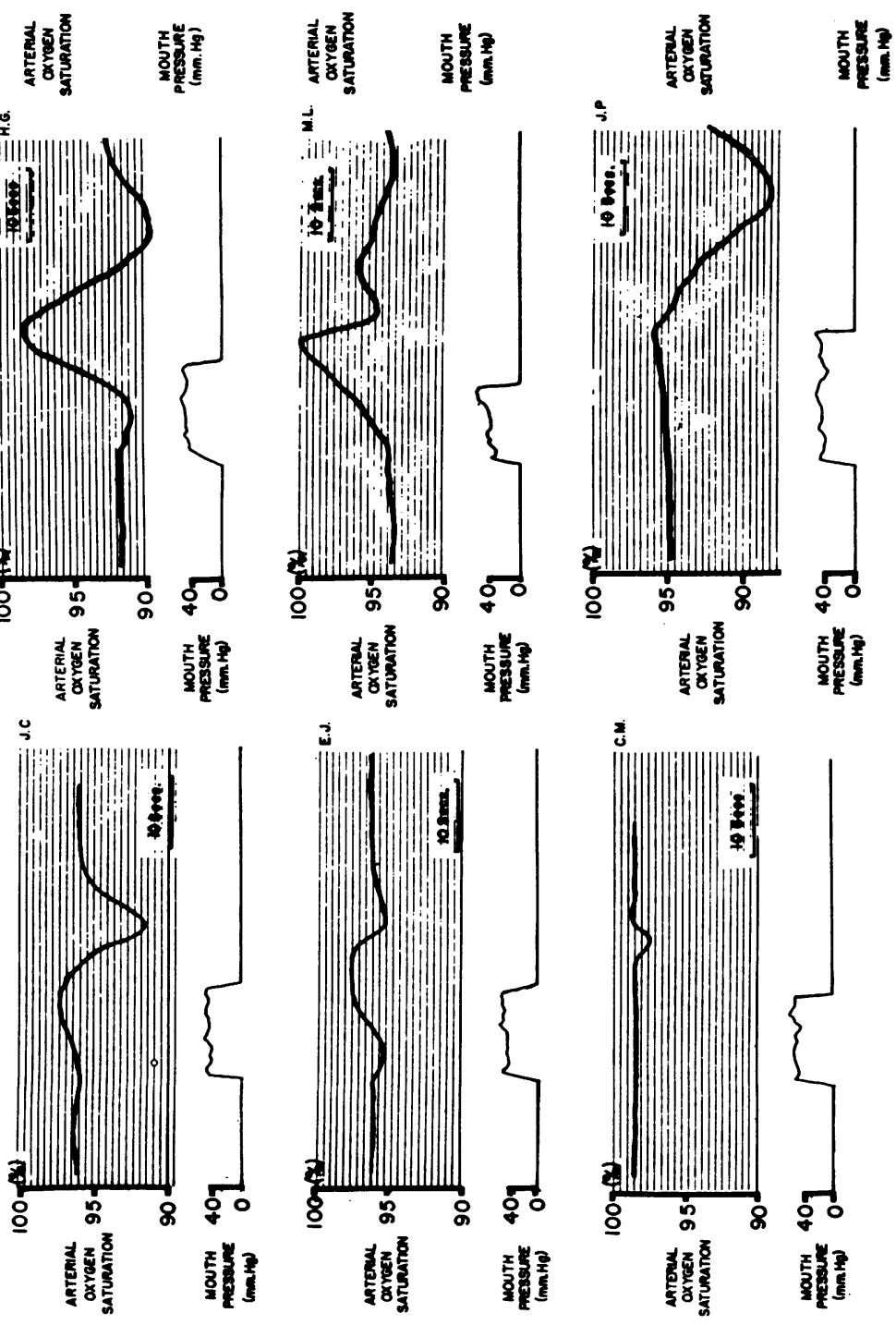

要兽

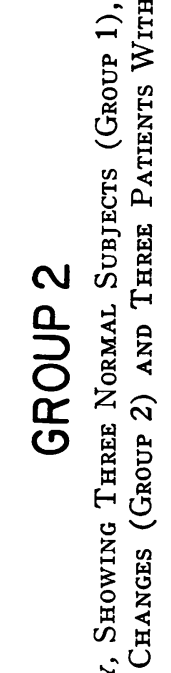
In In
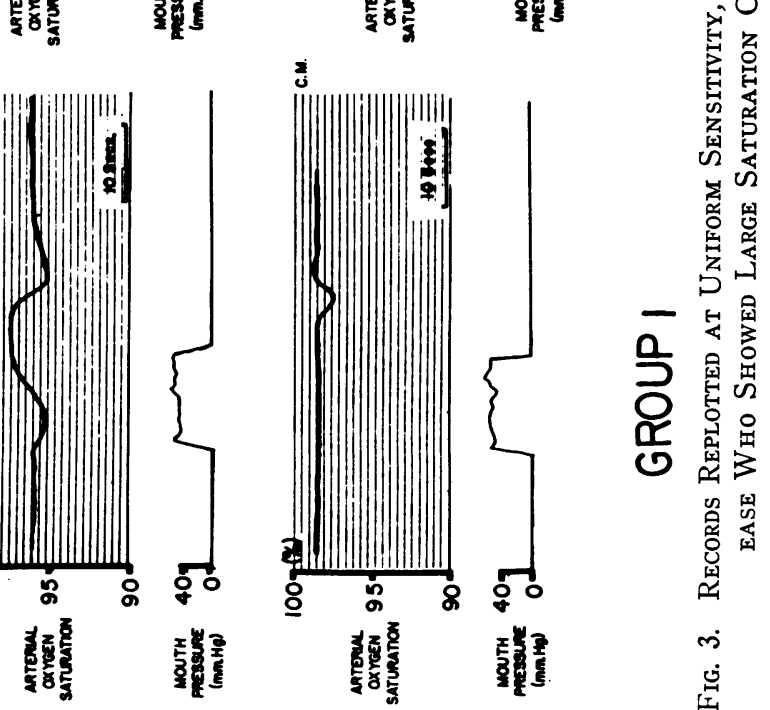
changes of the order of 10 per cent would be necessary. To rule out this possibility the studies were repeated in four patients using light of $800 \mathrm{~m} \mu$ wave length, so that the record would not be affected by changes in oxygen saturation, but would reflect changes in hematocrit with a sensitivity approximately two-thirds that at $620 \mathrm{~m} \mu$. The records of these four patients at $620 \mathrm{~m} \mu$ all showed significant changes during the Valsalva maneuver, larger than normal in two. At $800 \mathrm{~m} \mu$, however, three of the records were completely flat, while the fourth showed a very small deflection opposite in direction to that seen at $620 \mathrm{~m} \mu$.

Changes in flow rate of blood through the cuvette, if they were to occur during the maneuver, would also cause changes in optical density and lead to a similar false interpretation of the record. An increase in velocity of blood through the cuvette causes a diminution of the recorded optical density, owing probably to incomplete turbulence of blood in the cuvette at the rates of blood flow employed. This sensitivity to flow is equal at both $620 \mathrm{~m} \mu$ and $800 \mathrm{~m} \mu$ wave lengths; the absence of change in records taken at $800 \mathrm{~m} \mu$ therefore indicates that no changes in flow rate took place. Moreover, the syringe withdrawal unit was designed especially to avoid the occurrence of such flow changes, and with experience, its operator can readily detect any irregularity in its function. Changes in blood pressure in the cuvette cause no change in the record of optical density.

TABLE I*

\begin{tabular}{|c|c|c|c|c|c|}
\hline \multirow[b]{2}{*}{ Patient } & \multirow[b]{2}{*}{ Age } & \multirow[b]{2}{*}{ Diagnosis } & \multicolumn{3}{|c|}{ Arterial $\mathrm{O}_{2}$ saturation } \\
\hline & & & At rest & $\begin{array}{c}\text { Rise } \\
\text { during } \\
\text { maneuver }\end{array}$ & $\begin{array}{c}\text { Fall } \\
\text { after } \\
\text { maneuver }\end{array}$ \\
\hline \multicolumn{6}{|c|}{ Group 1} \\
\hline A. C. & 18 & Normal & $\begin{array}{l}\% \\
97\end{array}$ & 2.5 & None \\
\hline D. B. & 32 & Normal & 96 & 1.7 & 0.5 \\
\hline J. W. & 40 & Normal & 99 & 0.8 & 0.7 \\
\hline L. D. & 28 & Normal & 99 & 0.8 & 1.7 \\
\hline E. I. & 58 & Normal & 96 & 0.9 & 1.3 \\
\hline J. C. & 43 & Normal & 96 & 0.7 & 4.5 \\
\hline C. M. & 31 & Normal & 98 & None & 0.9 \\
\hline D. L. & 18 & Normal & 96 & 1.0 & 0.9 \\
\hline A. B. & 32 & Normal & 95 & 1.1 & 2.6 \\
\hline \multicolumn{6}{|c|}{ Group 2} \\
\hline B. B. & 47 & CHF, (Isch.) & 94 & None & None \\
\hline M. $\dot{V}$. & 58 & CHF, MI, AI & 85 & None & None \\
\hline A. $\mathrm{Br}$. & 27 & MS & 95 & 1.8 & 0.2 \\
\hline G. H. & 36 & MS, PH & 98 & 1.2 & 1.0 \\
\hline J. Pr. & 32 & MS (mild) & 98 & 1.9 & 1.5 \\
\hline B. Br. & 45 & Previous LVF (Isch.) & 97 & 1.4 & 0.4 \\
\hline L. E. & 56 & Cirrhosis of liver & 97 & 2.7 & None \\
\hline F. M. & 61 & Previous LVF (Isch.) & 92 & 2.1 & 0.5 \\
\hline R. F. & 48 & Previous LVF (Isch.) & 98 & 2.1 & None \\
\hline M. L. & 46 & Previous LVF (Isch.) & 94 & 6.0 & None \\
\hline H. G. & 58 & $\mathrm{PH}$, cause uncertain & 92 & 6.4 & 2.0 \\
\hline H. A. & 48 & $\mathrm{PH}$, lung fibrosis & 85 & 7.3 & None \\
\hline A. $\mathrm{Cu}$. & 27 & $\mathrm{PH}$ lung disease & 81 & 6.9 & 0.5 \\
\hline C. $Y$. & 41 & $\mathrm{PH}$, cause uncertain & 92 & 5.4 & None \\
\hline D. H. & 54 & Pulmonary emboli & 94 & 3.9 & 3.3 \\
\hline J.P. & 36 & Previous cor pulmonale & 93 & 0.5 & 7.2 \\
\hline \multicolumn{6}{|c|}{ Group 3} \\
\hline M. T. & 25 & ASD, Left-to- & 95 & 2.4 & None \\
\hline R.S. & 18 & ASD right & 95 & 1.6 & 1.5 \\
\hline M. G. & 19 & ASD shunt & 99 & 0.8 & 4.4 \\
\hline G. W. & 26 & ASD & 99 & 0.9 & 0.9 \\
\hline M. B. & 34 & VSD & 98 & 1.2 & 0.4 \\
\hline E. W. & 48 & ASD, $\mathrm{PH}$ & 92 & 5.5 & 7.9 \\
\hline I. N. & 38 & ASD, Ebstein's disease & 70 & 0.4 & 4.7 \\
\hline D. G. & 33 & VSD, PS & 90 & None & 10.7 \\
\hline I. S. & 22 & VSD, PH & 86 & 0.9 & 7.8 \\
\hline J. R. & 56 & VSD, $\mathrm{PH}$ & 87 & 2.7 & 8.2 \\
\hline J. B. & 28 & VSD, PH & 94 & 3.6 & 16.6 \\
\hline J. & 24 & PDA, PH & 96 & 3.5 & 13.3 \\
\hline
\end{tabular}

* Key to abbreviations: $\mathrm{CHF}=$ congestive heart failure; Isch. = coronary artery disease; $\mathrm{MI}=$ mitral insufficiency; $\mathrm{AI}=$ aortic insufficiency; $\mathrm{MS}=$ mitral stenosis; $\mathrm{PH}=$ pulmonary hypertension; $\mathrm{ASD}=$ atrial septal defect; $\mathrm{VSD}=$ ventricular septal defect; $\mathrm{PS}=$ pulmonic stenosis; $\mathrm{PDA}=$ patent ductus arteriosus. 


\section{PATIENT SELECTION}

Group 1 comprised two healthy members of the medical staff (C.M. and A.B.) and seven hospital patients who had no cardiovascular disease.

Group 2 patients all had obvious disease of the heart or lungs or both. Patients with severe emphysema were not included. The individual diagnoses are listed in Table I. The stated diagnosis was confirmed by autopsy in Patients M.L., A.Cu. and L.E., and at mitral valvotomy in A.Br. and G.H.; none of these five patients had a patent foramen ovale. Patients H.G., H.A., D.H. and J.Pr. were studied by cardiac catheterization and dye dilution techniques, and H.A. by angiocardiography; in none was there any evidence of an intracardiac shunt. The diagnosis in the remaining seven patients was made clinically. In J.P. the diagnosis of "Pickwickian syndrome" had been made one year prior to this study, after a complete hospital investigation. By strict dietary treatment, he had since lost over 100 pounds in weight and made a complete clinical recovery.

Group 3 included five patients with large left-to-right intracardiac shunts, and seven in whom the shunt was bidirectional (Table I).

\section{RESULTS}

The changes recorded in all the patients studied have been listed in Table I.

\section{Group 1}

A measurable change in saturation was recorded during or after the maneuver in every normal subject. The pattern of change was closely similar in each case ; a rise in saturation occurred during the maneuver in eight of the nine subjects and a fall in saturation followed release of the maneuver in eight of the nine; both changes were seen in seven patients. The saturation rise averaged 1.2 per cent, varying from 0 to 2.5 per cent; the saturation fall averaged 1.5 per cent, varying from 0 to 4.5 per cent. The three records of normal subjects shown on the left of Figure 3 illustrate the greatest (J.C.) and least (C.M.) changes observed in normal subjects.

\section{Group 2}

The two patients who were in congestive heart failure at the time of study showed no change whatever in saturation during or after release of the maneuver; they were the only patients studied in whom no change was observed. In one of them (B.B.), a right atrial pressure record was made during the maneuver and showed the characteristic "square-wave" pattern found in patients with congestive heart failure (7).

In the other 14 patients of this group, the changes seen were of the same pattern as those in normal subjects, with a rise in saturation during the maneuver in all 14 and a fall in saturation after release in 12 , reaching to below the resting level in nine. In seven of these 14 patients, the magnitude of the saturation changes was within the range seen in normal subjects, but in the remaining seven, changes of increased magnitude were recorded, rises of from 3.9 to 7.3 per cent occurring during the maneuver in six and a fall of 7.2 per cent following release in one. The records of three such patients, showing increased saturation changes, are illustrated in the center of Figure 3.

\section{Group 3}

The direction of saturation changes was again similar. Three of the four patients with predominant left-to-right shunt at atrial level showed changes differing in no way from those seen in normal subjects (e.g., Patient R. S. in Figure 3) ; the fourth (M.G. in Figure 3), differed not in the magnitude but in the abruptness of the fall in saturation following release. The one patient with left-to-right shunt at ventricular level showed changes identical to those in normal subjects.

The seven patients in whom the shunt was "balanced" showed changes in the same direction, but of generally greater magnitude, as illustrated by the record of J.M. in Figure 3. In this group, respiratory fluctuations of plus or minus 2 per cent were common during quiet respiration and increased markedly to plus or minus 4 to 7 per cent on hyperventilation.

\section{DISCUSSION}

\section{Patients without intracardiac shunts}

The arterial saturation changes recorded in the 23 patients with no intracardiac shunt (Groups 1 and 2) presumably arose in the lungs. Functional patency of the foramen ovale might permit a small right-to-left flow of blood after release of the Valsalva maneuver, as does an atrial septal defect (8), but this would be expected in less 
than 10 per cent of the adult population (9) and would not in any case explain the observed rise in saturation during the maneuver. Although a small amount of coronary venous blood is returned to the left side of the heart through the Thebesian vessels, this flow is probably too small to be of significance in the present results.

The intrapulmonary mechanisms which might account for our results may be divided into: changes in alveolar oxygen tension (alveolar $\mathrm{pO}_{2}$ ), in diffusion capacity, in velocity of capillary blood flow or in distribution of blood flow within the pulmonary vascular bed. Our evidence and that of other investigators tend to exclude the first three of these factors.

Although we did not measure oxygen tensions, the calculated effect of the initial $40 \mathrm{~mm}$. $\mathrm{Hg}$ rise in intrathoracic pressure is to raise a normal alveolar $\mathrm{pO}_{2}$ (104 mm.) by 5 to $6 \mathrm{~mm}$. at most; as the maneuver is held for 12 to 14 seconds, the $\mathrm{pO}_{2}$ gradually falls, reaching close to the control value; when intrathoracic pressure is released, there is an immediate fall followed by a small rise caused by a brief period of hyperventilation. The whole range of alveolar $\mathrm{pO}_{2}$ changes in normally ventilated alveoli probably does not exceed 5 to 6 mm., and this could not account for any measurable saturation changes in arterial blood. In poorly ventilated alveoli (e.g., $\mathrm{pO}_{2} 50 \mathrm{~mm}$.), the rise in $\mathrm{pO}_{2}$ due to increased intrathoracic pressure would be proportionally less (at most $3 \mathrm{~mm}$.) and, except with gross ventilation defect and marked arterial blood desaturation, this could not cause significant arterial saturation changes.

The Valsalva maneuver is unlikely to change gas distribution where this is already abnormal and we see no reason to suppose that the alveolar $\mathrm{pO}_{2}$ in such an area would be elevated by any mechanism other than that discussed above. Even if it were to occur, such a change would be smaller than that caused by several deep inspirations, and as has been described, these never caused saturation changes comparable in magnitude to those accompanying the Valsalva maneuver.

An alteration in the diffusion properties of the alveolar membrane sufficient to account for the observed saturation changes seems improbable, because of the rapidity, the brief duration and the reversibility of the changes.
The absence of saturation changes in the two patients studied during congestive heart failure suggests that the changes are dependent upon the hemodynamic effects of the Valsalva maneuver, which are not obtained in such patients (7), rather than the ventilatory effects.

Simple changes in velocity of blood flow through pulmonary capillaries during and after the maneuver would not significantly alter the end-capillary oxygen content, as equilibrium between alveolar and capillary oxygen tension is achieved so rapidly $(1,10)$. The decreased pulmonary blood flow of systemic shock, for example, or the increased pulmonary flow in congenital left-to-right shunts, do not per se produce abnormal pulmonary venous oxygen saturation.

The explanation of our findings which we believe to be correct is that a redistribution of blood flow occurs within the pulmonary vascular bed during the maneuver. If in the resting state a small proportion of the pulmonary blood flow were distributed to unventilated shunt vessels, and if during the maneuver the flow through such vessels were diminished, the oxygen saturation of the mixed arterial blood would rise and the magnitude of the rise would be determined by the amount by which such shunt flow was reduced relative to the total flow. Similarly, an increase in the relative flow through the shunt pathways following release of the maneuver would cause a fall in the arterial saturation.

There is no direct evidence in the present results to indicate which particular feature of the hemodynamic responses to the Valsalva maneuver is responsible for the redistribution of flow. As described by Lee, Matthews and Sharpey-Schafer (11), both transmural pressure and flow in the pulmonary artery fall progressively during the maneuver and overshoot after release before returning to their resting levels. In Figure 2, the fall in transmural pressure correlates closely in pattern with the rise in arterial saturation, and the overshoot in pressure with the saturation fall. The same correlation between changes in transmural pulmonary artery pressure and in arterial saturation is found in patients with mitral stenosis on exercise (12) and on change of posture (13), in patients with atrial septal defect and pulmonary hypertension on exercise (14), and in dogs fol- 
lowing injection of glass beads into the pulmonary artery (15). It is tentatively suggested therefore, that transmural pressure changes may influence patency of the intrapulmonary shunts, at least under the conditions studied here. Good evidence already exists that shunt vessels may be directly influenced by acetylcholine (16) and by the oxygen tension of inhaled gas (15).

All the six patients who showed saturation rises greater than the normal range had the clinical signs of pulmonary hypertension and this was confirmed by direct measurement in five (pulmonary artery systolic pressure above $50 \mathrm{~mm}$. $\mathrm{Hg}$ ). It is possible that the pulmonary hypertension itself may have been related etiologically to the presence in these patients of a large shunt flow. The Patient J. P. in Figure 3 (Group 2), who showed a fall of 7.2 per cent after release of the maneuver, may have had a patent foramen ovale. It is interesting, however, that he had suffered one year previously from an episode of cor pulmonale caused by obesity and hypoventilation; since then he had lost over 100 pounds in weight and had made a complete clinical recovery. An alternative explanation for the saturation fall is that it indicated the persistence of pulmonary shunt vessels developed during the earlier episode of cor pulmonale.

Uniformity of the hemodynamic response to the Valsalva maneuver must be assumed before the present findings can be compared quantitatively. Obvious exceptions occur in congestive heart failure, where little or no response is seen (7), and in emphysema, where greatly increased responses may occur (17). In the absence of emphysema, however, hemodynamic changes are rarely greater than normal and it is safe to assume that large saturation changes indicate large shunt flows.

The flow through shunt vessels at rest can be estimated from the rise in saturation and the cardiac output. In the group of normal subjects, the average rise of 1.2 per cent in saturation indicates a shunt flow at rest equal to about 1 per cent of the total pulmonary flow. In two of the six patients in whom a larger saturation rise was found, the cardiac output was measured and similar calculations indicated shunt flows at rest equal to 15 per cent and 20 per cent of the pulmonary flows.
The relation of the shunt vessels discussed to alveolar capillaries and to the bronchial circulation cannot be evaluated in the present study. If, however, the distribution of pulmonary blood flow between these vessels and ventilated alveolar capillaries is altered by simple changes in pressure or flow in the pulmonary artery, this would suggest that the two pathways differ anatomically and that the shunt vessel concerned is not, in fact, an unventilated capillary.

\section{Patients with congenital cardiac shunts}

In the patients of Group 3, the changes recorded in arterial saturation must represent redistribution of blood flow both within the lungs and across the intracardiac shunt, no distinction between the two being possible by the present method. Changes in the intracardiac shunt obviously predominated in some instances, producing much larger changes in saturation than were seen in patients of Groups 1 and 2 . When the intracardiac shunt was predominantly from left to right, however, the saturation changes were often no larger than those seen in normal subjects. For this reason we cannot agree with the suggestion of Lee and Gimlette (8) that arterial saturation changes detected by the ear oximeter following release of the Valsalva maneuver are helpful in the diagnosis of atrial septal defect.

If pulmonary hypertension behaves in this group of patients as is suggested in those of Group 2, a large arteriovenous shunt may develop in the lungs. This intrapulmonary shunt may explain the pulmonary venous desaturation described in cases of atrial septal defect with pulmonary hypertension $(14,18)$, the arterial desaturation persisting after ligation of a patent ductus arteriosus complicated by pulmonary hypertension (19), and the presence of arterial desaturation in cases of ventricular septal defect with pulmonary hypertension insufficient to cause a reversal of the intracardiac shunt (20). This possibility should be considered before assuming that arterial desaturation indicates reversal of an intracardiac shunt.

\section{SUM MARY}

Arterial saturation changes have been recorded during the performance of the Valsalva maneuver 
in 38 subjects, using a cuvette densitometer to give a direct and continuous record of oxygen saturation from arterial blood.

A consistent pattern of change in saturation was found in patients without intracardiac shunts, consisting of a rise in saturation during the maneuver and a fall in saturation following release of the maneuver. In nine normal subjects, the saturation rise averaged 1.2 per cent, while in six of the patients with cardiac or pulmonary disease, saturation rises of from 3.9 to 7.3 per cent occurred during the maneuver.

The most probable explanation for these findings is that the saturation rise results from a decrease in blood flow through pulmonary arteriovenous shunts, secondary to the hemodynamic effects of the Valsalva maneuver, and that those patients who showed a large rise in saturation had an abnormally large flow through such shunts at rest. The observations are consistent with the hypothesis that transmural pulmonary artery pressure is an important factor controlling flow through these shunts, and that an abnormally large shunt flow may develop in patients with chronic pulmonary hypertension.

Evidence of shunt flow at rest was found in eight of nine normal subjects and averaged approximately 1 per cent of total pulmonary blood flow.

In 14 patients with cardiac or pulmonary disease but without intracardiac shunts or signs of congestive heart failure, each case showed evidence of shunt flow at rest. The shunt was abnormally large in six of the 14 , amounting to 20 per cent of total pulmonary flow in one subject. Two patients with congestive heart failure showed no change in saturation, presumably because the Valsalva maneuver produced no hemodynamic change in the pulmonary circulation.

The arterial saturation changes seen in 12 patients with congenital intracardiac shunts represented a summation of changes in shunt flow within the lungs and across the congenital defect, frequently dominated by the latter.

\section{ACKNOWLEDGMENTS}

We are indebted to Doctors Richard L. Riley and Richard H. Shepard for much helpful discussion and ad- vice during the course of this work, and to Miss Mary Lou Sparger for technical assistance.

\section{REFERENCES}

1. Lilienthal, J. L., Jr., Riley, R. L., Proemmel, D. D., and Franke, R. E. An experimental analysis in man of the oxygen pressure gradient from alveolar air to arterial blood during rest and exercise at sea level and at altitude. Amer. J. Physiol. 1946, 147, 199.

2. Prinzmetal, M., Ornitz, E. M., Jr., Simkin, B., and Bergman, H. C. Arterio-venous anastomoses in liver, spleen, and lungs. Amer. J. Physiol. 1948, $152,48$.

3. Tobin, C. E., and Zariquiey, M. O. Arterio-venous shunts in the human lung. Proc. Soc. exp. Biol. (N. Y.) $1950,75,827$.

4. Sabiston, D. C., Jr., Khouri, E. M., and Gregg, D. E. Use and application of the cuvette densitometer as an oximeter. Circulat. Res. 1957, 5, 125.

5. Wood, E. H., and Geraci, J. E. Photoelectric determination of arterial oxygen saturation in man. J. Lab. clin. Med. 1949, 34, 387.

6. Elisberg, E. I., Goldberg, H., and Snider, G. L. Value of intraoral pressure as a measure of intrapleural pressure in man. J. appl. Physiol. 1951, $4,171$.

7. Sharpey-Schafer, E. P. Effect of Valsalva's maneuver on the normal and failing circulation. Brit. med. J. 1955, 1, 693.

8. Lee, G. de J., and Gimlette, T. M. D. A simple test for interatrial communications. Brit. med. J. 1957, 1, 1278.

9. Thompson, T., and Evans, W. Paradoxical embolism. Quart. J. Med. 1930, 23, 135.

10. Farhi, L. E., and Riley, R. L. Graphic analysis of moment-to-moment changes in blood passing through the pulmonary capillary, including a demonstration of three graphic methods for estimating the mean alveolar capillary diffusion gradient (Bohr integration). J. appl. Physiol. 1957, 10, 179.

11. Lee, G. de J., Matthews, M. B., and Sharpey-Schafer, E. P. The effect of the Valsalva maneuver on the systemic and pulmonary arterial pressure in man. Brit. Heart J. 1954, 16, 311.

12. Donald, K. W., Bishop, J. M., and Wade, O. L. A study of minute to minute changes of arteriovenous oxygen content difference, oxygen uptake and cardiac output and rate of achievement of a steady state during exercise in rheumatic heart disease. J. clin. Invest. 1954, 33, 1146.

13. Cardus, D., Mackinnon, J., and Wade, G. Circulatory effects of changing position in mitral disease. Brit. Heart J. 1958, 20, 233.

14. Luchsinger, P. C., Moser, K. M., and Buhlmann, A. Physiologic definition of pulmonary vascular status 
in atrial septal defect (abstract). Circulation 1957, 16, 912.

15. Niden, A. H., and Aviado, D. M., Jr. Effects of pulmonary embolism on the pulmonary circulation with special reference to arteriovenous shunts in the lung. Circulat. Res. 1956, 4, 67.

16. Wood, P. Pulmonary hypertension with special reference to the vasoconstrictive factor. Brit. Heart J. 1958, 20, 557.

17. Stucki, P., and Luthy, E. Les variations de la tension arterielle chez l'emphysemateux lors de l'empreuve de valsalva. Arch. Mal. Coeur. 1955, 48, 441.
18. Jonsson, B. in Diagnosis of Congenital Heart Disease, A Clinical and Technical Study by the Cardiologic Team of the Pediatric Clinic, Karolinska Sjukhuset, Erica Odelberg, Trans. Chicago, Year Book Publishing Company, 1955, pp. 285 and 338.

19. Limon Lason, R. Pulmonary hypertension in patent ductus arteriosus in Pulmonary Circulation, W. Adams and I. Veith, Eds. New York, Grune and Stratton Inc., 1959, p. 216.

20. Mannheimer, E., Ikkos, D., and Jonsson, B. Prognosis of isolated ventricular septal defects. Brit. Heart J. 1957, 19, 333. 